commit safety violations. In addition to the assets value loss resulting from unsafe damage, some of the safety violations are very serious and may well cause serious unrecoverable consequences. In India, a building greater than $75 \mathrm{ft}(23 \mathrm{~m})$, generally 7 to 10 stories, is considered as high-rise. Also, a building is considered to be high-rise when it extends higher than the maximum reach available to fire fighters. According to the building code of India, a tall building is one with four floors or more, or a high-rise building is one 15 meters or more in height. Most of the tall buildings in India are in the commercial capital Mumbai. More than 2500 high-rise buildings are already constructed.

\section{OBJECTIVES AND SCOPE OF THE STUDY}

The ultimate goal for every enterprise should be to have "zero incidents". This goal provides the incentive to achieve the best possible performance and ensures continuous vigilance towards greater safety. Seeking to achieve this goal and managing safety requires a constant effort that involves establishing safety-related objectives, implementing those objectives, and measuring and reviewing progress in meeting those objectives. This should be reflected in the long-term, overall Safety Policy. In order to ensure day-to-day implementation of the Policy, concrete goals and objectives should be established and agreed upon by the entire organization.

This is to provide a tool for measurement for the contractors to plan the safety measures and integrate the safety concerns in the construction process.

Specifically, the objectives of this project are:

Identify the key behavioral factors affecting the performance of people during a fire in a high-rise building and the singularities associated to this type of buildings.

$>$ Review the current procedures and strategies currently adopted in high-rise buildings (e.g. horizontal and vertical evacuation methods, phased evacuation, total evacuation, defendingplace, etc.).

$>$ Review the capabilities of the currently available evacuation models to simulate high-rise building evacuations.

\subsection{Scope of work:}

1. Less planning time, Shorter installation times.

2. Increased comfort and energy, efficiency
3. Increased security and protection for people, data and construction processes.

4. Customers can concentrate on the core business.

5. Lower operating expenses.

6. Increased reliability of technical infrastructure.

7. Higher productivity.

8. Increased protection of investment throughout the building's entire life span.

\section{REVIEW OF LITERATURE}

I studied different literature review for safety challenges in high rise building. Safety is one of the major aspects in high rise buildings in construction sector. The main researchers among them are:

According to Professor N. Krishnamurthy: Safety in high rise design and construction $\mathrm{He}$ concluded that every/designer shall ensure that any design he prepares should among the design consideration.

According to Romel G. Solis: Construction Worker's Perception of Safety He concluded that there should be safety awareness at sites to prevent and minimize risks.

According to Ian Mclver: Investigating the application of building Regulation $\mathrm{He}$ prepared a document which aimed at both the developers and the building regulations.

\subsection{Site Visits:}

I visited following sites for my research work:

\section{UTC Sofftech Pvt Ltd NOIDA Expressway}

Laureute builwell

Pvt Ltd

NOIDA Sec-108

Arabian Construction

Companies

NODIA, Sec-94

Ashiyan

NODIA, Sec-16

Ashiyan

NODIA, Sec-19

$\mathrm{ABL}$

Humhama, sgr, J\&K

$>\mathrm{ABL}$

Bemina, sgr, J\&K

$>\mathrm{ABL}$

Barzulla Baghat, sgr, J\&K

M.M. Shalls

Dalgate

JKPCC

Handawara 


\subsection{Preparation of Questionnaire:}

I prepared 31 questions and distributed in different 10 sites and got the result from different respondents (Junior Engineer, AEE, Supervisor, and Project Manager).

\subsection{Data collection:}

I collected the data from 80 respondents from different 10 sites from New Delhi(NCR), NOIDA, Srinagar, Handwara.

\subsection{Limitation of the Study:}

In my research work I faced the following problems:

$>$ Collection of data from different sites of the companies was difficult.

$>$ Management was hesitant to share data.

> Management was not willing to share their views on my topic which become major difficulty in completion of my work.

\subsection{Result of the survey:}

The result of my survey report is lack of safety awareness among workers on site. There is only $34.5 \%$ awareness of safety on sites.

\section{QUESTIONNARIE}

Note: - Rate the below questions as per your site. Each star equals to $20 \%$.

Q1. Is High Rise Building evacuation different from other buildings?

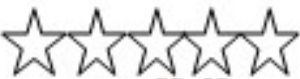

Q2. If stair travel potentially dangerous are there alternatives?

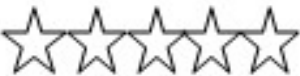

Q3. If existing downstairs take so long, am I better of going up to the roof and waiting for rescues there?

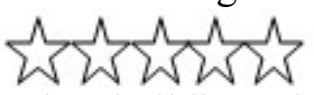

Q4. Should high rise buildings have any type of exterior device?

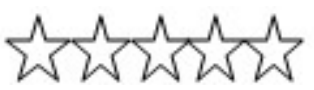

Q5. Will buildings egress system work in a terrorist attack?

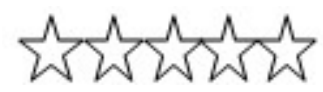

Q6. Is there any particular arrangement for the persons /occupants with disabilities during emergency?

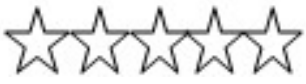

Q7. How much percentage work is executed according to the safety code?

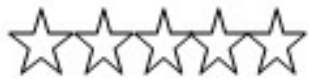

Q8. Is safety provided against falling from windows and terraces?

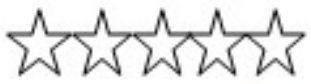

Q9. Is safety provided against electric accidents due to lose electric fitting, hanging wires extra?

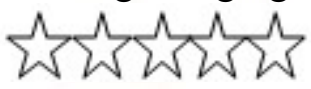

Q10. What percentage of treatment can we provide in emergency on site?

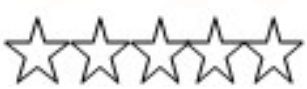

Q11. Are workers aware about the safety precautions?

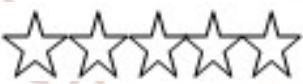

Q12. Is safety education provided to the labors before work?

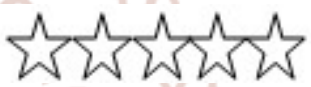

Q13. Should therebe any age limit for labors in high rise building?

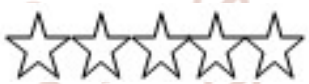

Q14. How much percentage of laboursare aware about the insecure actions causing major accidents?

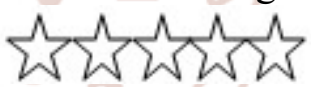

Q15. Is high rise building safe for occupants?

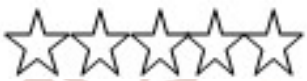

Q16. What percentage of workers are using for personal protection equipment's?

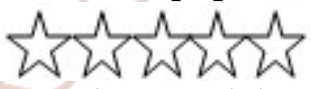

Q17. How much experience a labor need in high rise building construction?

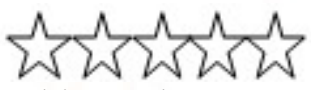

Q18. Are you taking the proper inspection of formwork properly?

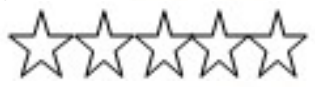

Q19. Is glaring the illumination on your eyes?

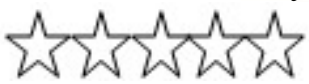

Q20. Irresponsible behavior of workers in evidently risky situation?

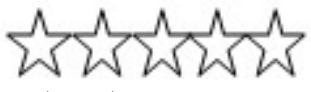

Q21. Temporary structures are used many times which got damaged and weak at critical 
International Journal of Trend in Scientific Research and Development (IJTSRD) ISSN: 2456-6470

locations ultimately lead to accidents or failures.

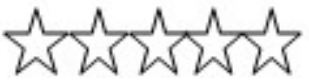

Q22. Is there any safety plan and program or policy at the construction site?

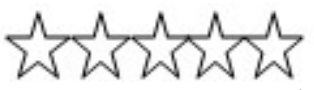

Q23. Is there any emergency plan to cope with unanticipated circumstance?

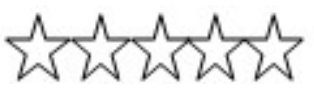

Q24. Is there any special arrangement to capture falling debris from height?

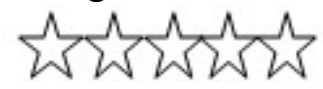

Q25. Periodically and frequently safety check conducted at the site or not?

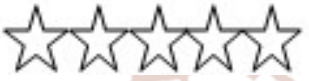

Q26. Can fatigue or boredom is a main cause to an accident?

\section{RESULT AND DISCUSSION}

Table 5.1 Names, Symbols, Company, Type of Projects etc. of sites

\begin{tabular}{|c|c|c|c|c|c|c|c|}
\hline S.No & Symbol & Name & Designation & Phone No & Company Name & Type of Project & Location \\
\hline 1 & $S \cdot 1$ & SPanda & Project Head & \multicolumn{2}{|c|}{9971694379 UTC Softtech Prt ltd } & Common High Rise & NOIDA Expressway \\
\hline 2 & S.2 & Raj kumar & planning engineer & \multicolumn{2}{|c|}{8447752846 Laureute builwell put itd } & Residential & NOIDA Sec-108 \\
\hline 3 & $5 \cdot 3$ & Saptrshin neagi & Asstmanager HSE & \multicolumn{2}{|c|}{$8587835023 \mathrm{ACC}$} & Residential & NODIA Sec:94 \\
\hline 4 & $5 \cdot 4$ & Intiyaz Ahmad Mir & J.E & \multicolumn{2}{|c|}{9622440991 AB. } & Residential Apartment: & Humhama,ser, J\&K \\
\hline 5 & S.5 & Basharat Aii & AEE & \multicolumn{2}{|c|}{9596959290 ABL. } & Residential Apartment: & Bemina,sge, J\&K \\
\hline 6 & S.6 & Afaq Khandey & J.E & \multicolumn{2}{|c|}{9906522296 ABL. } & Residential Apartment: & Barzula Baghat,seg, ISK \\
\hline 7 & $5 \cdot 7$ & Jameel khan & J.E & \multicolumn{2}{|c|}{9419656433 M.M.Shalls } & Official & Dalgate \\
\hline 8 & 5.8 & Umair Ansari & J.E & \multicolumn{2}{|c|}{9560722069 Ashiyan } & Tower Const: & NODIA Sec: 16 \\
\hline 9 & $5 \cdot 9$ & Adil iqbal & J.E & \multicolumn{2}{|c|}{ 9015585021 Ashiyan } & Tower Cons: & NODIASEC- 16 \\
\hline 10 & $s \cdot 10$ & Riffat khalid & AEE & \multicolumn{2}{|c|}{$9419059165 \mathrm{jkpcc}$} & hospital & handawara \\
\hline
\end{tabular}


Table $5.2 \%$ age of safety awareness among workers on site, analysis

$12 \begin{array}{lllllllllllllllllllllllllllllllllll} & 3 & 4 & 5 & 6 & 7 & 8 & 9 & 10 & 11 & 12 & 13 & 14 & 15 & 16 & 17 & 18 & 19 & 20 & 21 & 22 & 23 & 24 & 25 & 26 & 27 & 28 & 28 & 30 & 31 & 32 & 33 & 34 & 35 & 36\end{array}$

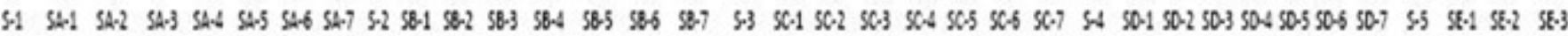

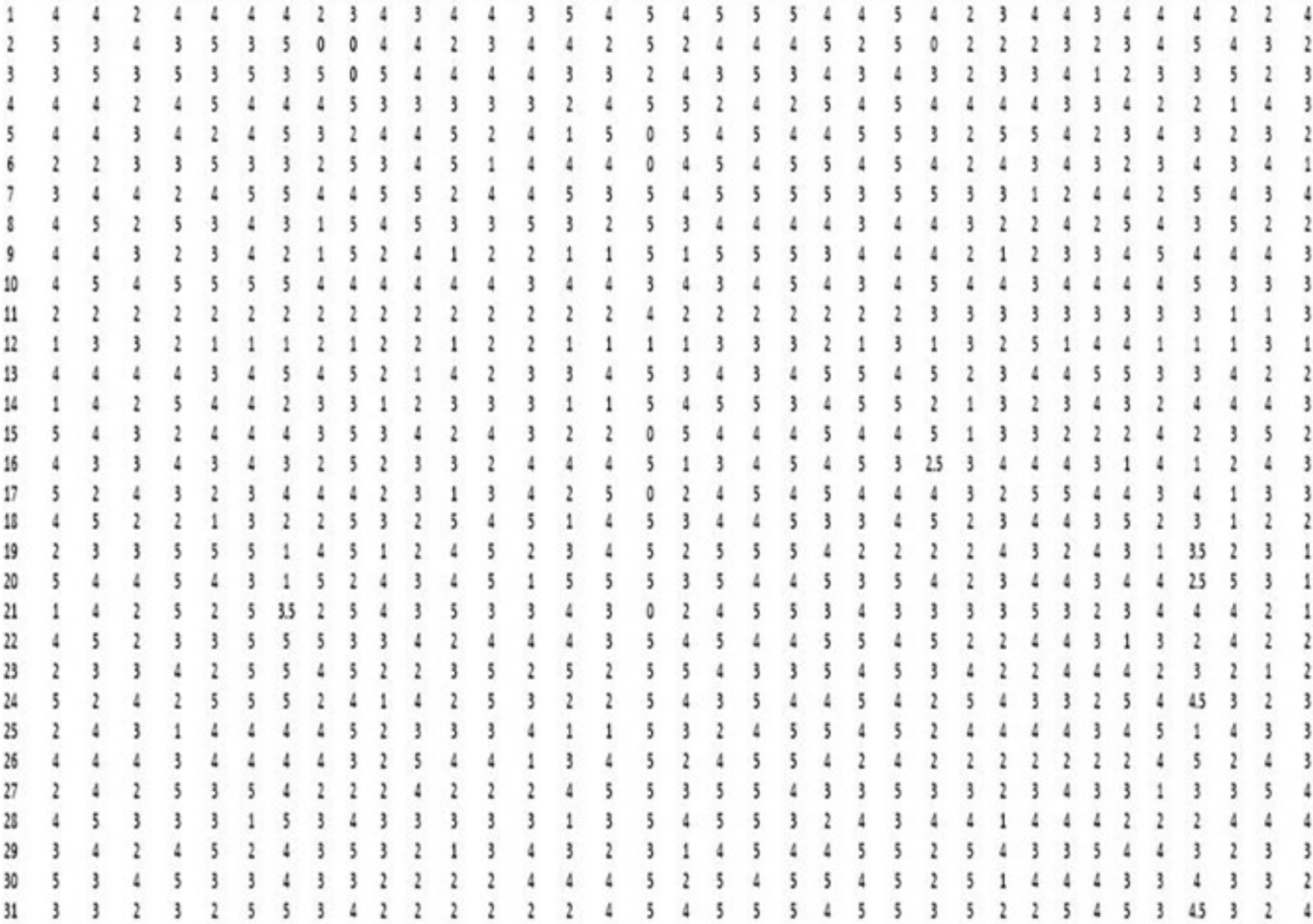




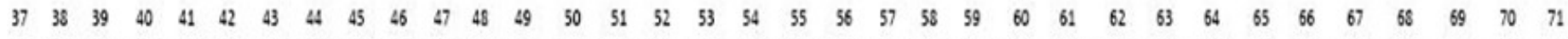

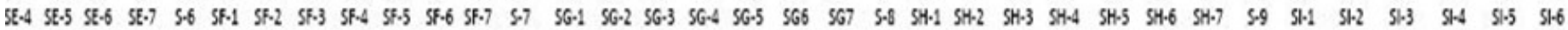

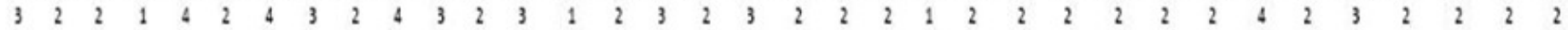

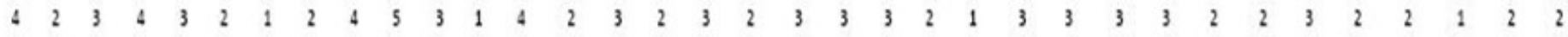

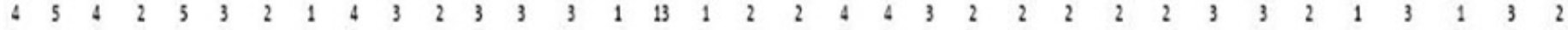

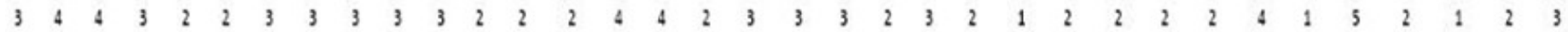

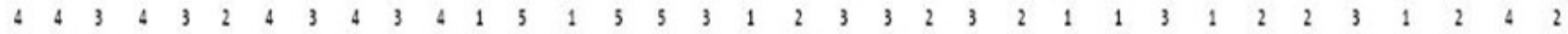

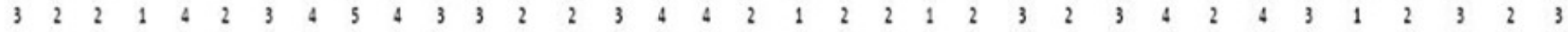

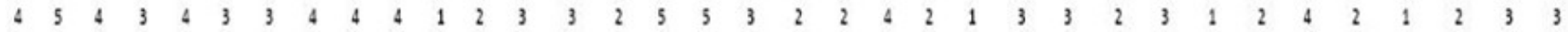

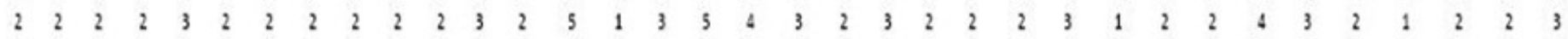

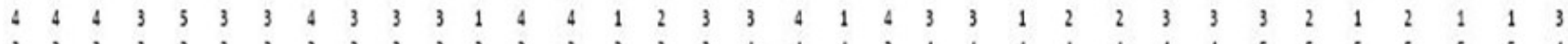

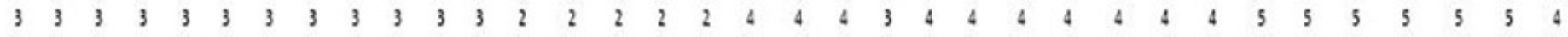

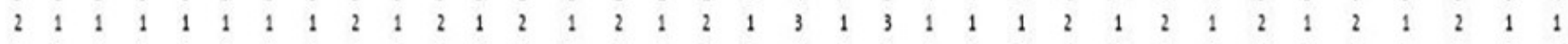

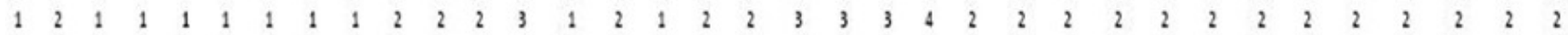

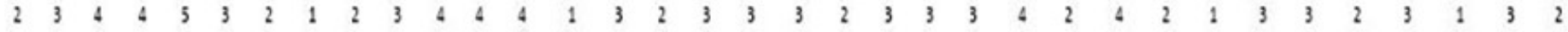

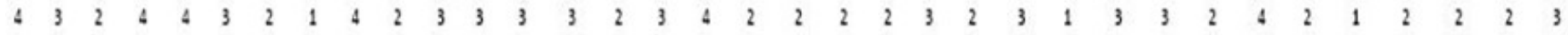

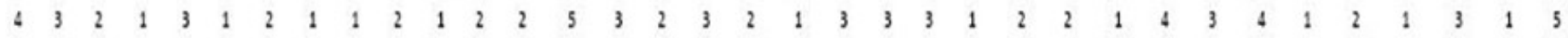

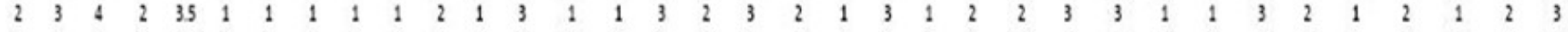

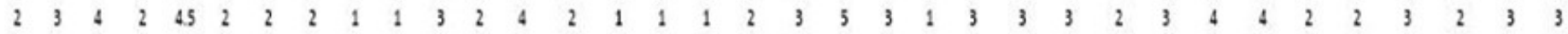

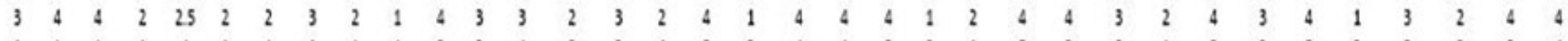

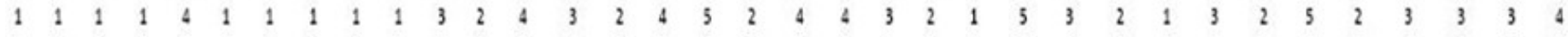

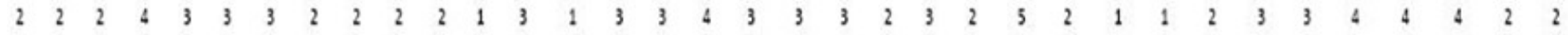

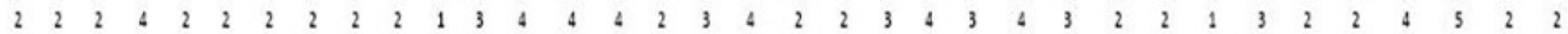

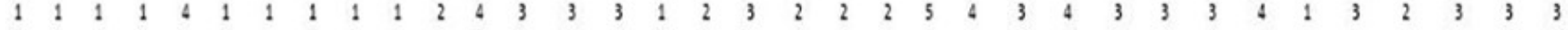

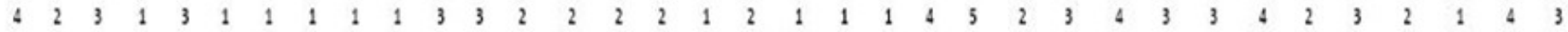

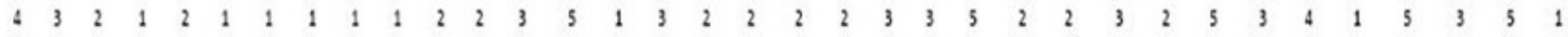

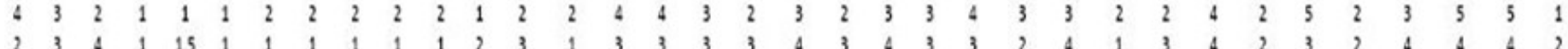

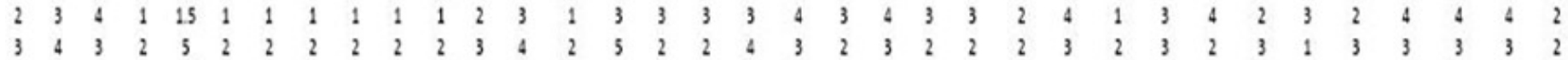

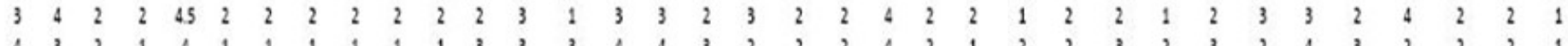

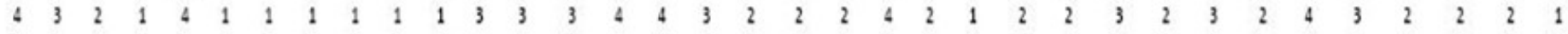

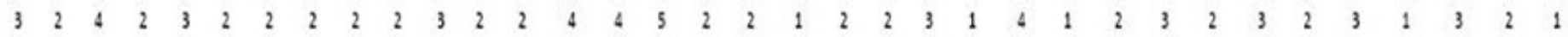

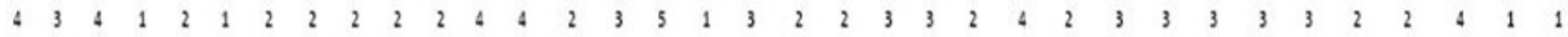

$\begin{array}{lllllllll}72 & 73 & 74 & 75 & 76 & 77 & 78 & 79 & 80\end{array}$

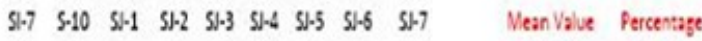

$\begin{array}{ccccccccccc}2 & 4 & 2 & 3 & 2 & 1 & 2 & 2 & 2 & 2.96 & 59.25 \\ 3 & 3 & 3 & 3 & 1 & 2 & 3 & 3 & 3 & 2.55 & 57 \\ 2 & 5 & 2 & 4 & 1 & 2 & 2 & 3 & 3 & 3.09 & 61.75 \\ 2 & 3 & 1 & 4 & 2 & 1 & 2 & 4 & 4 & 3.03 & 60.5 \\ 3 & 5 & 2 & 4 & 3 & 2 & 1 & 3 & 2 & 3.09 & 61.75 \\ 2 & 3 & 3 & 3 & 3 & 3 & 2 & 1 & 5 & 3.00 & 60 \\ 3 & 2 & 3 & 2 & 1 & 1 & 3 & 2 & 1 & 3.25 & 65 \\ 4 & 5 & 2 & 1 & 2 & 3 & 4 & 3 & 1 & 2.95 & 59 \\ 4 & 4 & 1 & 1 & 4 & 3 & 4 & 5 & 4 & 2.98 & 59.5 \\ 4 & 4 & 4 & 4 & 2 & 2 & 2 & 2 & 2 & 3.66 & 73.25 \\ 2 & 2 & 2 & 0 & 0 & 0 & 0 & 0 & 0 & 1.73 & 34.5 \\ 2 & 2 & 2 & 2 & 2 & 2 & 3 & 2 & 2 & 1.94 & 38.75 \\ 3 & 3 & 3 & 3 & 1 & 2 & 3 & 2 & 3 & 3.14 & 62.75 \\ 3 & 2 & 4 & 3 & 1 & 1 & 2 & 3 & 3 & 2.53 & 56.5 \\ 5 & 2 & 5 & 5 & 5 & 2 & 5 & 3 & 5 & 2.94 & 58.75 \\ 2 & 2 & 2 & 2 & 2 & 2 & 2 & 1 & 2 & 2.55 & 51 \\ 3 & 5 & 3 & 2 & 3 & 5 & 2 & 5 & 1 & 2.97 & 59.375 \\ 3 & 4 & 4 & 3 & 3 & 3 & 3 & 5 & 3 & 3.11 & 62.125 \\ 2 & 3 & 5 & 4 & 2 & 3 & 3 & 4 & 4 & 2.91 & 58.125 \\ 2 & 3 & 4 & 4 & 1 & 1 & 4 & 3 & 5 & 3.14 & 62.875 \\ 1 & 5 & 3 & 1 & 1 & 1 & 3 & 2 & 4 & 2.89 & 57.575 \\ 2 & 3 & 2 & 1 & 2 & 2 & 3 & 2 & 2 & 2.90 & 58 \\ 2 & 2 & 1 & 2 & 3 & 2 & 4 & 1 & 5 & 2.80 & 56 \\ 3 & 1 & 2 & 2 & 4 & 4 & 5 & 1 & 4 & 3.02 & 60.375 \\ 4 & 5 & 3 & 2 & 3 & 4 & 4 & 4 & 1 & 3.05 & 61 \\ 4 & 5 & 2 & 2 & 2 & 4 & 4 & 4 & 2 & 2.96 & 59.125 \\ 5 & 2 & 1 & 1 & 1 & 5 & 5 & 4 & 3 & 3.00 & 60 \\ 4 & 4 & 2 & 2 & 1 & 4 & 4 & 2 & 4 & 2.86 & 57.125 \\ 3 & 4 & 3 & 3 & 2 & 3 & 4 & 2 & 5 & 2.90 & 58 \\ 2 & 3 & 4 & 1 & 2 & 2 & 5 & 2 & 4 & 2.94 & 58.75 \\ 2 & 3 & 4 & 2 & 3 & 1 & 5 & 1 & 3 & 3.01 & 60.125\end{array}$

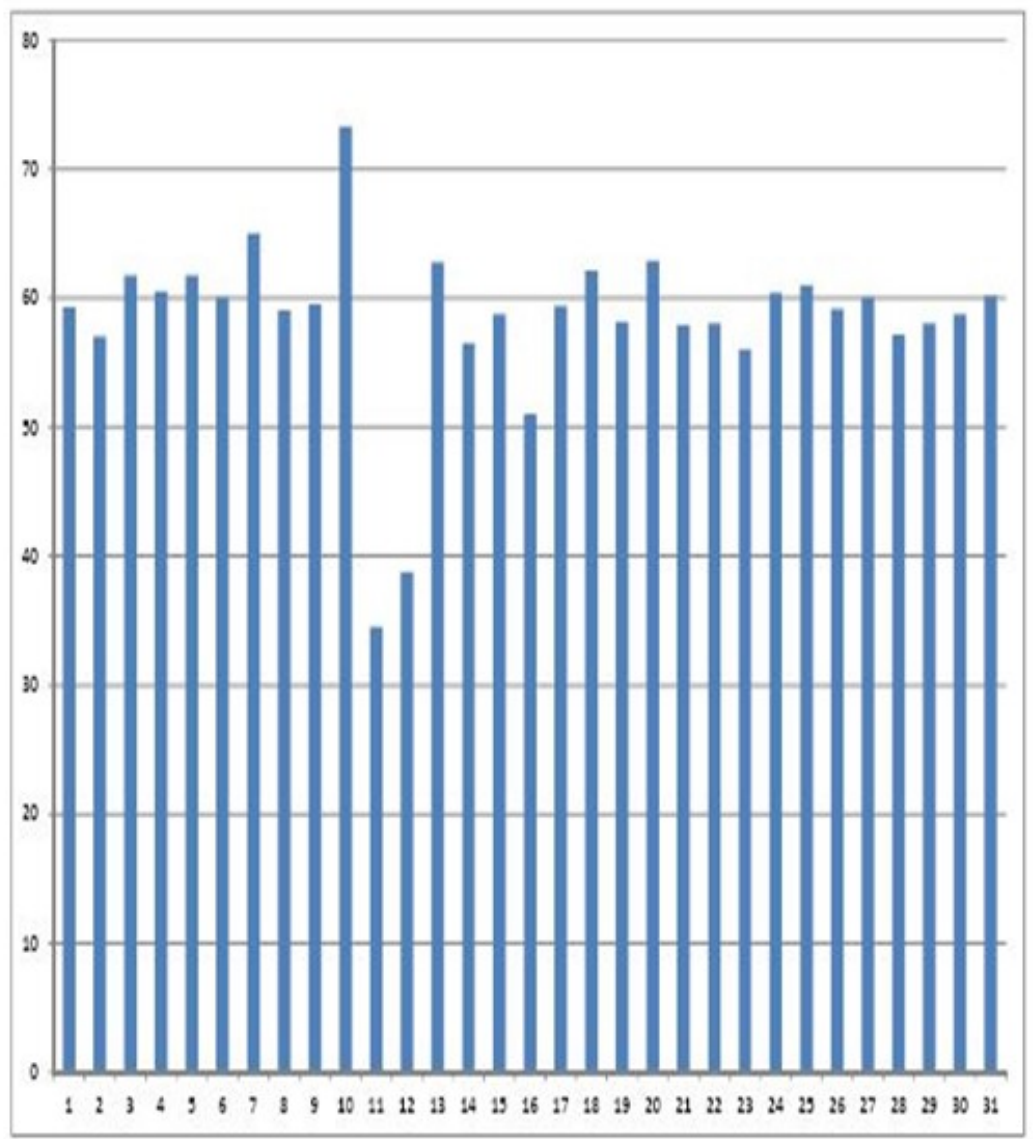




\section{CONCLUSION}

From my project I concluded that there is lack of safety awareness among workers on site. Workers should provide Safety Management System (SMS) for safety purposes.

The SMS is a must for every construction project, especially for high-rise construction because this area is consisting of many latent hazard and risk. Without SMS, the owners, developers, investors, shareholders, and managers cannot reach the goal and target as expected. On the other hand, the contractors, suppliers, installers, and workers cannot fulfill and complete their mission.

In overall, without SMS, the construction of a highrise will become very dangerous and the casualty/damage cannot be prevented. The SMS must be set up and strictly implemented and it should comprise of the main frames:

$>$ Safety Policy

$>$ Safety Organization

$>$ Safety Plan \& Program

$>$ Hazard \& Risk analysis and identification

$>$ Safety Documenting \& Recording

$>$ Safety Review \& Upgrading

In addition, high-rise construction project should also have strong and powerful $\mathrm{PM} / \mathrm{CM}$ team who will monitor, control, and handle the safety matters (e.g. review and approval of safety plan/program submitted by the contractors and sub-contractors). It is also their duty to strictly implement these safety plans which normally and basically include the following:

Safety management/hierarchy/organization

$>$ PPE availability, use and conditions

$>$ Scaffolding (fixed and mobile) including ladders $\&$ platforms

$>$ Electro-mechanical activities and controls

$>$ Site status

$>$ Temporary power supply and tools

$>$ Health \& welfares

$>$ Storage condition

$>$ Fire prevention

\section{$>$ Waste/pollution control \\ $>$ Monitoring and control of working on height \\ $>$ Aid/first aid and evacuation \\ $>$ Emergency plan for unanticipated circumstances}

The PM as the owner representative should have strong and effective ways to force all contractors and their subs at site to totally and absolutely comply with safety rules. It is necessarily to cleverly apply the method of fine and reward to guarantee the safe situation at site workplace.

\section{REFERENCE}

\section{Professor N. Krishnamurthy}

Safety in High-Rise Design and Construction Consultant: Safety, Structures, and Computer Applications, Singapore www.profkrishna.com

2. Rómel G. Solís-Carcaño*, Ricardo J. FrancoPoot

Construction Workers' Perceptions of Safety (2014) College of Engineering, Autonomous University of Yucatan, Merida, Mexico Email: *tulich@uady.mx Received 13 November 2013; revised 22 December 2013; accepted 13 January 2014

\section{Ian McIver:}

Investigating the Application of Building Regulations at Lammas (Under the direction of Dr. Bev West) (2014)

4. Adan, E. (2004).

Factors affecting Safety on Construction Projects. Department of Civil Engineering,

\section{K. Al-Kodmanyand M. Ali}

"Skyscrapers and place making supporting local culture and identity," Archnet IJAR International Journal of Architectural Research, vol. 16, issue 2,July 2012.

\section{Masayuki Nakao,}

"Chain Reaction Collapse of a High-rise Apartment due to a Gas Explosion, May 16, 1968 in Ronan Point, East London, England", Institute of Engineering Innovation, School of Engineering, The University of Tokyo 